\title{
An investigation of cognitive failures and its related factors in industry employees in Qom Province, Iran, in 2016
}

\author{
Mahdinia M, $\mathrm{MSc}^{1}$, Mirzaei Aliabadi, M, $\mathrm{PhD}^{2}$, Darvishi E, $\mathrm{MSc}^{3}$, Mohammadbeigi A, \\ $\mathrm{PhD}^{4}$, Sadeghi A, MSc${ }^{5}$, Fallah H, $\mathrm{MSc}^{6}$ \\ 1-MSc in Occupational Health, Dept. of Occupational Health, Faculty of Health, Qom University of Medical Sciences, Qom, \\ Iran. 2- Assistant Prof., of Occupational Health, Center of Excellence for Occupational Health Engineering, Research Center \\ for Health Sciences, Faculty of Health, Hamadan University of Medical Sciences, Hamadan, Iran. 3- MSc in Occupational \\ Health, Environmental Health Research Center, Kurdistan University of Medical Science, Sanandaj, Iran. 4- Associated \\ Prof., of Epidemiology, Faculty of Health, Qom University of Medical Sciences, Qom, Iran. 5- MSc in Industrial Safety \\ Engineering, Faculty of Health, Safety and Environment, Shahid Beheshti University of Medical Sciences, Tehran, Iran. 6- \\ MSc in Occupational Health, Dept. of Occupational Health, Faculty of Health, Yazd University of Medical Sciences, Yazd, \\ Iran
}

$\begin{array}{lll}\text { Abstract } & \text { Received: February 2017, Accepted: September } 2017\end{array}$

Background: Cognitive failure is mental lapses in perception, attention, memory, and action. It occurs during routine tasks that one would usually have no difficulty in successfully completing. Cognitive performance is influenced by conditions and some individual and job characteristics and the identification of factors that affect human performance is essential to prevent human error. The purpose of this study was to evaluate cognitive failures and identify individual and job related factors in industry employees.

Materials and Methods: This cross-sectional study was conducted in 173 employees of an industry in Qom Province in Central Iran in 2016. The demographic information were collected via interviews and related questionnaires. Moreover, cognitive failures were assessed using the Cognitive Failures Questionnaire (CFQ). Data analysis was performed using factor analysis, t-test, Pearson correlation, and multiple linear regressions.

Results: Factor analysis showed that cognitive failures have three domains (memory, attention, and action). Cronbach's alpha coefficient for the whole questionnaire was 0.89 . The mean \pm SD score of cognitive failures in the study group was $1.07 \pm 0.55$. The statistical analysis of the data revealed that there was a significant correlation between smoking, chronic disease, and work experience and cognitive failures $(\mathrm{P}<0.05)$.

Conclusions: Cognitive failures have a multi-dimensional structure and these dimensions have an integral relationship. It seems that chronic disease, smoking, and work experience cause an increase in the risk of cognitive failures, but this issue requires further and more comprehensive studies.

Keyword: Cognitive, Industry, Employees, Individual, Job

\section{Introduction}

Although the role of human error in the occurrence of accidents is very clear and the catastrophic results of the lack of reviews of human error during calculation of risk are well documented, human errors are not addressed during the evaluation of safe parameters in many cases (1). Human error is the result of a combination of various factors such as management and organizational factors, the complexity of the work method, environmental conditions, equipment and machinery design, staff training, supervision, and the presence or absence of operational instructions. In the investigation of accidents, to obtain a comprehensive understanding of the circumstances of an accident, detailed information of human errors should be

\footnotetext{
* Corresponding author: Mohsen Mahdinia, Dept. of Occupational Health, Faculty of Health, Qom University of Medical Sciences, Qom, Iran.

E-mail: mohsen.mahdinia@yahoo.com
} 
collected and errors be identified by reviewing the provided information about accidents, and then, effective prevention strategies should be developed (2).

Cognitive failure is mental lapses in perception, attention, memory, and action (3). It could be the result of internal thoughts or external distractions (4) and occur during routine tasks that one would usually have no difficulty in successfully completing (5). For instance, cognitive failure may be the inability to remember the name of a familiar person, the date, or the equipment layout in the workplace (6). Today, cognitive errors are the inseparable component of industry and business, and employees might be faced with them at any phase of the work. Cognitive failure is one of the causes of accidents in the workplace.

A cognitive error can cause an accident to occur due to lack of attention which can lead to injuries or only minor injuries (7). In a study on navy personnel, Day et al. indicated that the probability of the occurrence of accidents is higher in individuals with more cognitive failures (8). In another study on nurses, park et al. concluded that medical errors are due to cognitive failures, and cognitive failures are due to shift work, lack of autonomy in work, and job instability (6). It should be added that not all cognitive failures lead to an accident (9). A study on drivers came to the conclusion that although cognitive failures are associated with the rate of driving errors, they are not associated with traffic accidents (10).

It seems that cognitive failure is related to personal characteristics and stressors. People with higher work ethic are less likely to have cognitive failure and accidents, because they carry out their assigned duty more accurately (11). Errors are unwanted results of information processing or cognitive function in humans; thus, different types and extent of errors which are committed by people in similar situations can be associated with individual differences in cognitive abilities. Thus, since the inconsistency between job demands and an individual's capabilities is the cause of error, ergonomic perspective should be considered (10).

Individuals' behaviors are influenced by different conditions; therefore, identification and evaluation of affective factors on human performance is a necessity to prevent or reduce human error and improve safety in the industries (12).

There are contradictions in the results of studies that have evaluated cognitive failures and its relation to accidents in the industries. Hence, this study aimed to investigate cognitive failures as a part of human errors and identify individual and job related factors in an industry in Iran.

\section{Material and Methods}

This cross-sectional study was carried out on 173 employees in Qom Province, Iran, in 2016. Data were gathered using demographic and job questionnaires, and the Cognitive Failures Questionnaire (CFQ).

The individual and occupational variables included age, gender, marital status, education, smoking, chronic disease, medication use, type of occupation, work experience, shift work, daily working hours, and second job. The entry criterion was at least 1 year of work experience. Furthermore, cognitive failures were assessed using the standard CFQ. The Persian version of the CFQ was developed by Hassanzadeh et al. and they studied the validity and reliability of the questionnaire and reported a Cronbach's alpha coefficient of 0.96 (13). The CFQ consists of 30 items that are scored based on a five-point Likert scale ranging from 0 to $4(0=$ never, $1=$ rarely, $2=$ sometimes, $3=$ often, and $4=$ always). These questions are used to assess the incidence of lapses in memory, attention, and action in individuals and are related to common mistakes such as forgetting a phone number or names, mistakes in occupational tasks, or other cases where the person is usually performing their job correctly. This questionnaire has three dimensions including memory, attention, and performance. The minimum and 
maximum score of the original questionnaire with 30 items is 0 and 120 , respectively.

To conduct the study and collect data, the industry employees were invited to the health and safety department, and after presenting the necessary explanations about the study and its purpose, they were asked to complete the questionnaire carefully through self-reported.

Self-report method was used to evaluate the incidence of accidents and the participants were asked to provide information on any accidents they have had in the year leading up to the time of the study. Self-reported method has been introduced as a reliable method in studies for accidents investigation (14, 15). Participation in the study was voluntary and the participants signed an informed written consent before participation.

Data analysis was performed using Pearson correlation, independent sample t-test, and multiple linear regression analysis in SPSS software (version 20, IBM Corporation, Armonk, NY, USA). Cronbach's alpha coefficient was used to assess the questionnaire's internal consistency. Given that the histogram of the data was normal, the normality of data was tested and verified by the Shapiro-Wilk test at 5\% error level. The assumption of the equality of variances was evaluated and confirmed by Levene's test.

\section{Results}

The mean \pm SD of age and work experience of the 173 participations were $30.84 \pm 5.05$ years and $6.90 \pm 3.90$ years, respectively. Among the participants, $75.4 \%$ were men and $24.6 \%$ were women. In addition, $30.6 \%$ were single and $69.4 \%$ were married. In terms of education level, $15.7 \%$ had an education level of below diploma, 43.6\% had a diploma, and 40.7\% were university graduates. In addition, $33.7 \%$ of subjects were administrative sector personnel and $66.3 \%$ were production workers. Moreover, $22.5 \%$ of those surveyed said they had at least 1 accident in the year leading to the present study.

A Cronbach's alpha of 0.89 was obtained for the whole questionnaire, which demonstrated that the reliability of the used questionnaire was appropriate.

In this study, to present the cognitive failure score for every subject, scores ratio was used rather than raw scores. Thus, the sum of earned scores for each person was divided by the number of questions and the resulting number was reported as the cognitive failure score. The results of this section are presented in table 1.

Table 1: The scores of different dimensions of cognitive failures of the participants

\begin{tabular}{cccc}
\hline & \multicolumn{3}{c}{ Score of Cognitive Failure } \\
\cline { 2 - 4 } & Min & Max & Mean \pm SD \\
\hline Memory & 0.00 & 3.14 & $1.11 \pm 0.62$ \\
\hline Attention & 0.00 & 4.00 & $1.19 \pm 0.72$ \\
\hline action & 0.00 & 3.50 & $0.83 \pm 0.55$ \\
\hline Cognitive Failure & 0.00 & 3.19 & $1.07 \pm 0.55$ \\
\hline
\end{tabular}

The results of the Pearson correlation coefficient between personal and job characteristics (age, experience, daily working hours, education, disease, medication, smoking, and etc.), and cognitive failures is presented in tables 2 and 3 . As seen in table 2, only in the memory domain, a significant correlation with work experience was obtained. 
Table 2: Pearson correlation coefficient between cognitive failures and some demographic and job variables in participants

\begin{tabular}{ccccc}
\hline & & Age & $\begin{array}{c}\text { Work Experience } \\
\text { (Year) }\end{array}$ & $\begin{array}{c}\text { Daily Working Hours } \\
\text { (Hour) }\end{array}$ \\
\hline \multirow{2}{*}{ Memory } & Pearson correlation coefficient & 0.12 & 0.16 & 0.15 \\
\cline { 2 - 5 } & $\mathrm{P}$ & 0.11 & 0.04 & 0.06 \\
\hline \multirow{2}{*}{ Attention } & Pearson correlation coefficient & 0.06 & 0.15 & 0.03 \\
\cline { 2 - 5 } & $\mathrm{P}$ & 0.42 & 0.06 & 0.66 \\
\hline \multirow{2}{*}{ Action } & Pearson correlation coefficient & -0.34 & -0.00 & 0.03 \\
\cline { 2 - 5 } & $\mathrm{P}$ & 0.66 & 0.99 & 0.61 \\
\hline \multirow{2}{*}{ Cognitive failure } & Pearson correlation coefficient & 0.08 & 0.14 & 0.08 \\
\cline { 2 - 5 } & $\mathrm{P}$ & 0.30 & 0.07 & 0.25 \\
\hline
\end{tabular}

* The correlation is significant

To determine the relationship between accidents and cognitive failures, the cognitive failure score of the participants who had had accidents were compared using t-test. As shown in table 3 , there was no significant relationship between accidents and cognitive failures.

Table 3: The relationship of cognitive failures with demographic and job variables in participants

\begin{tabular}{|c|c|c|c|}
\hline Independent Variabl & & $\begin{array}{c}\text { Cognitive Failure } \\
(\text { Mean } \pm \text { SD) }\end{array}$ & $\mathbf{P}$ \\
\hline \multirow{2}{*}{ Smoking } & Yes & $1.50 \pm 0.54$ & \multirow{2}{*}{$<0.001$} \\
\hline & No & $1.05 \pm 0.57$ & \\
\hline \multirow{2}{*}{ Chronic disease } & Yes & $1.47 \pm 0.77$ & \multirow{2}{*}{$<0.001$} \\
\hline & No & $1.04 \pm 0.52$ & \\
\hline \multirow{2}{*}{ Permanent drug use } & Yes & $1.36 \pm 0.62$ & \multirow{2}{*}{0.042} \\
\hline & No & $1.05 \pm 0.54$ & \\
\hline \multirow{2}{*}{ Second job } & Yes & $0.86 \pm 0.40$ & \multirow{2}{*}{0.033} \\
\hline & No & $1.10 \pm 0.56$ & \\
\hline \multirow{2}{*}{ Accidents in the past year } & Yes & $0.96 \pm 0.44$ & \multirow{2}{*}{0.081} \\
\hline & No & $1.11 \pm 0.58$ & \\
\hline
\end{tabular}

Other individual and job variables included age, sex, marital status, education, and occupation and employment status did not show significant relationships with cognitive failures. In the next step, multiple linear regression analysis was used to remove the interaction of variables and to study the correlation of personal and job variables with cognitive failures, the results of which are presented in table 4.

Table 4: The results of the linear regression model of effective variables on cognitive failures in participants

\begin{tabular}{ccccccc}
\hline $\begin{array}{c}\text { *Independent } \\
\text { variable }\end{array}$ & B Coefficient & SD & $\begin{array}{c}\text { Beta } \\
\text { Coefficient }\end{array}$ & P & \multicolumn{2}{c}{$\begin{array}{c}\text { 95\% confidence interval for } \\
\text { B Coefficient }\end{array}$} \\
\hline Smoking & 0.35 & 0.16 & 0.16 & 0.032 & 0.07 & Upper Border \\
\hline Chronic disease & 0.50 & 0.15 & 0.25 & 0.001 & 0.81 & 0.02 \\
\hline Work experience & 0.02 & 0.01 & 0.17 & 0.034 & 0.04 & 0.00 \\
\hline
\end{tabular}

\section{Discussion}

In this study, the internal reliability and factor structure of the CFQ were analyzed in the original sample and the results showed that cognitive failure has three dimensions of memory, attention, and action. The results of this section confirm the results of other studies that consider a multi-dimensional structure for 
cognitive failures. Hassanzadeh et al. studied cognitive failures in urban bus drivers (16). They obtained the three dimensions of memory, attention, and action-estimation (16). In another study, Allahyari et al. obtained five dimensions for cognitive failures including memory, deficits in attention, dynamic function, social interaction, and names (10). Broadbent, who has presented the 25 -item CFQ for the first time, has offered a structure consisting of three dimensions (17). Wallace presented the Workplace Cognitive Failure Scale (WCFS) with 15 questions, in his factor analysis, he has presented a three-dimensional structure (memory, attention, and action) for cognitive failures in the workplace (18).

The results of this study showed that the mean score of cognitive failures in the study groups was $1.07 \pm 0.55$ and these results are consistent with similar studies. Allahyari et al., in their study on taxi-drivers, used the 25-item CFQ and raw scores and reported the mean score of $27.94 \pm 15.7$ for cognitive failures (10). Polina, in a study on students, reported a mean score of 19.12 for cognitive failures (19), which is less than the average obtained in the present study. Larson, in his study on US Navy personnel, reported a mean score of $12.83 \pm 33.6$ for cognitive failures (20). Moreover, Wallace, in a study on a sample consisting of students and US Navy personnel, and Matthews, in his study on students, reported the mean scores of $43.46 \pm 17.02$ and $45 \pm 9.72$ for cognitive failures, respectively $(21,22)$. It should be noted that all four studies have reported the score of cognitive failures based on the total score of 25 questions.

In the present study, in the first stage and without consideration of the interaction of various variables, statistical analysis showed that cognitive failures were associated significantly with variables such as smoking, chronic disease, permanent drug use, and second job. However, the other studied variables did not have a significant relationship with cognitive failures. In addition, multiple linear regression analysis showed that among all the studied variables, the three variables of chronic disease, smoking, and work experience were predictors of cognitive failures. Among these three variables, the most effective variable was chronic diseases and the least effective was work experience. According to the results, the risk of cognitive failures was higher in those suffering from a disease and those who smoked compared to others. Furthermore, with increasing work experience, the risk of cognitive failures also increased.

In relation to the increased risk of cognitive failures in people who suffered from a disease, a study similar to this study in terms of methodology was not found. Nevertheless, other studies that have focused on the effect of disease and pain on the intellectual functions have reported similar results and there is strong evidence that chronic pain may affect the different aspects of cognitive functions such as memory, concentration, decision making, and performance (23). Etherton et al., in their study, concluded that patients with chronic pain often have impaired attention and memory (24). This result was also confirmed in a study by Dick (25). However, Sjøgren, in his study, did not observe a significant difference in working memory between people with chronic disease and the control group (26).

Regarding the increase in cognitive failure in people who consume tobacco, the results of the present study are inconsistent with the study by Simpson in which a significant correlation was not observed between smoking and cognitive failures (27). However, the results of some studies have indicated that cigarette smoking influences the cognitive and mental functions. In this context, Ahmadi, in a study on a sample of people, came to the conclusion that cognitive functions of the brain are significantly lower in smokers than nonsmokers (28). Fakhari, in his study, concluded that smokers compared to nonsmokers have poorer short-term memory performance (29). Heffernan also concluded that daily working memory errors were significantly more in smokers than 
nonsmokers, and smoking has a negative effect on short-term memory (30). Hill found that smoking has destructive effects on the group of perceptual functions that are necessary for processing measures (31). However, some studies have reported different results regarding the consumption of cigarettes and cognitive function. For example, Wang came to the conclusion that smoking has a protective role for cognitive functions against increasing age (32). Momtaz also concluded that smoking reduces the risk of cognitive impairment (33). Therefore, there are still notable differences in the results of different studies regarding the correlation between these two variables, and thus, this issue requires more comprehensive and more accurate studies.

However, in this study, work experience was one of the job variables associated with cognitive failures and the results showed that, with increasing work experience, the risk of cognitive failure increased. Nevertheless, Simpson came to the conclusion that work experience was not significantly correlated with cognitive failures (27). Evidently, work experience and age have a significant and strong correlation with cognitive failures. In various studies, the correlation between cognitive failures and age is similar to the correlation between cognitive failures and work experience; this correlation has been accepted in some studies and rejected in others. In this study, there was no significant correlation between age and cognitive failures. In this regard, Elfring came to the conclusion that the rate of cognitive failure decreases with increase in age (11), but, in another study, no significant correlation was observed between age and cognitive failures (34). Furthermore, Simpson in his study did not find a significant correlation between age and cognitive failures (27).

Another finding of this study was that there was no significant correlation between cognitive failures and accidents. In this regard, Allahyari, in his study on taxi drivers, came to the conclusion that there was not a direct correlation between cognitive failures and driving accidents, but there was a significant correlation between cognitive failures and the rate of driving errors (10). Hassanzadeh, in a study on urban bus drivers, came to the conclusion that driving accidents were not significantly correlated with cognitive failures, but were related with unsafe behaviors and intentional and unintentional violations of driving regulations (16). However, many studies have been performed in this regard and have found significant correlation between accidents and cognitive failures and that the risk of cognitive failures is high in persons who have experienced accidents $(8,35)$.

One potential limitation of this study was selfreport assessment of cognitive failures by workers, as it may create information bias. The tool used to evaluate cognitive failures in various studies varied in terms of the number and nature of questions. Although the general CFQ designed by Broadbent (17) has been used in many studies, the 15-item WCFS in three domains (memory, attention, and action) designed by Wallace (18) has also been used in some studies $(6,8,34)$. Therefore, it is suggested that in future studies the validity and reliability of the CFQ be evaluated in Iran. In addition, because there are other methods to assess cognitive function, it is recommended that in future studies, in addition to using designed questionnaires to evaluate cognitive failures, other methods also be used and the results be analyzed.

The second limitation was the use of selfreport method for reporting involvement in accidents that may lead to not reporting or not recalling the accidents. Thus, the use of other methods such as investigation of recorded events, safety sampling, or supervisor ratings on safety behavior for measures of safety performance is suggested in future studies. Moreover, in order to achieve more precise results, it is recommended that future studies be conducted in different and larger samples of industry employees. 


\section{Conclusion}

The results of this study showed that cognitive errors are affected by some personal and occupational factors such as smoking, illness, and work experience. However, no significant relationship was found between cognitive errors and incidents. Therefore, further studies are needed for definitive findings especially in industrial environments.

\section{Acknowledgements}

This study was financially supported by Qom University of Medical Sciences (The Research Council Grant No 94591) and the authors would like to thank the university for its support and the workers for their cooperation.

Conflict of interest: None declared.

\section{References}

1. Ghasemi M, Nasl Saraji G, Zakerian A, Azhdari MR. Control of human error and comparison level risk after correction action with the SHERPA method in a control room of petrochemical industry. Iran Occupational Health 2011; 8(3):14-22.

2. Shirali GA, Karami E, Goodarzi Z. Human errors identification using the human factors analysis and classification system technique (HFACS). Journal of Health and Safety at Work 2013; 3(3):45-54.

3. Bruce AS, Ray WJ, Carlson RA. Understanding cognitive failures: what's dissociation got to do with it? Am J Psychol 2007; 120(4):553-63.

4. Hong JCh, Tai KH, Hwang MY, Kuo YCh, Chen JS. Internet cognitive failure relevant to users' satisfaction with content and interface design to reflect continuance intention to use a government e-learning system. Comput Human Behav 2017; 66:353-62.

5. Carrigan N, Barkus E. A systematic review of the relationship between psychological disorders or substance use and self-reported cognitive failures. Cogn Neuropsychiatry 2016; 21(6):539-64.

6. Park YM, Kim SY. Impacts of job stress and cognitive failure on patient safety incidents among hospital nurses. Saf Health Work 2013; 4(4):210-5.

7. Chaplin K, Smith AP. Breakfast and snacks: associations with cognitive failures, minor injuries, accidents and stress. Nutrients 2011; 3(5):515-28.

8. Day AJ, Brasher K, Bridger RS. Accident proneness revisited: the role of psychological stress and cognitive failure. Accid Anal Prev 2012; 49:532-5.

9. Smith AP. Effects of noise, job characteristics and stress on mental health and accidents, injuries and cognitive failures at work. Paper Presented at: The $10^{\text {th }}$ International Congress on Noise as a Public Health Problem; 2011 July 24-28; London, United Kingdom.

10. Allahyari T, Saraji GN, Adl J, Hosseini M, Iravani $\mathbf{M}$, Younesian $\mathrm{M}$, et al. Cognitive failures, driving errors and driving accidents. Int J Occup Saf Ergon 2008; 14(2):149-58.

11. Elfering A, Grebner S, Schwander L, Wattinger M. Sports after busy work: workrelated cognitive failure corresponds to risk bearing behaviors and athletic injury. Escr Psicol 2014; 7(1):43-54.

12. Kiani M, Mohammad Fam I, Allahviranloo T. Identification and evaluation of performance indicators affecting human error, based on fuzzy logic (an operation center of Gas transmission company). Occupational Medicine 2014; 5(4):60-7.

13. Hassanzadeh Rangi N, Allahyari T, Khosravi Y, Zaeri F, Saremi M. Development of an Occupational Cognitive Failure Questionnaire (OCFQ): evaluation validity and reliability. Iran Occupational Health 2012; 9(1):29-40.

14. Vinodkumar MN, Bhasi M. A study on the impact of management system certification on safety management. Saf Sci 2011; 49(3):498507.

15. Mearns K, Whitaker SM, Flin R. Safety climate, safety management practice and safety performance in offshore environments. Saf Sci 2003; 41(8):641-80.

16. Hassanzadeh N, Farshad N, Khosravi $\mathrm{Y}$, Shafaeegholami P, Zare Gh. The survey of relationship between occupational cognitive failures and safety performance among bus drivers. Iran Occupational Health 2013; 10(6):13-23.

17. Broadbent DE, Cooper PF, FitzGerald P, Parkes KR. The Cognitive Failures Questionnaire (CFQ) and its correlates. $\mathrm{Br} \mathrm{J}$ Clin Psychol 1982; 21(Pt 1):1-16.

18. Wallace JC, Chen G. Development and validation of a work-specific measure of cognitive failure: implications for occupational safety. J Occup Organ Psychol 2005; 78(4):615-32.

19. Pollina LK, Greene AL, Tunick RH, Puckett JM. Dimensions of everyday memory in young adulthood. Br J Psychol 1992; 83(Pt 3):305-21. 
20. Larson GE, Alderton DL, Neideffer M, Underhill E. Further evidence on dimensionality and correlates of the Cognitive Failures Questionnaire. British Journal of Psychology 1997; 88(1):29-38.

21. Wallace JC, Kass SJ, Stanny CJ. The cognitive failures questionnaire revisited: dimensions and correlates. J Gen Psychol 2002; 129(3):238-56.

22. Matthews G, Coyle K, Craig A. Multiple factors of cognitive failure and their relationships with stress vulnerability. J Psychopathol Behav Assess 1990; 12(1):49-65.

23. Pertovaara A. Mechanisms of cognitive impairment in chronic pain patients can now be studied preclinically by inducing cognitive deficits with an experimental animal model of chronic neuropathic pain. Scand J Pain 2016; 10:106-7.

24. Etherton JL, Bianchini KJ, Ciota MA, Heinly MT, Greve KW. Pain, malingering and the WAIS-III working memory index. The Spine Journal 2006; 6(1):61-71.

25. Dick BD, Rashiq S. Disruption of attention and working memory traces in individuals with chronic pain. Anesth Analg 2007; 104(5):12239.

26. Sjøgren P, Christrup LL, Petersen MA, Højsted J. Neuropsychological assessment of chronic non-malignant pain patients treated in a multidisciplinary pain centre. Eur J Pain 2005; 9(4):453-62.

27. Simpson SA, Wadsworth EJ, Moss SC, Smith AP. Minor injuries, cognitive failures and accidents at work: incidence and associated features. Occup Med (Lond) 2005; 55(2):99108.
28. Ahmadi E, Bazazemonsef F. The survey of cognitive executive functions of brain in male smokers and non-smokers. Journal of RafsanjanUniversity of Medical Sciences 2015; 14(9):803-10.

29. Fakhari A, Farshbaf Khalili A, Farshbaf Khalili A, Agazadeh H, Khoshavar H, Abiar H, et al. Comparison of Short- Term Memory Quotient (SMQ) between smoker and non-smoker men. Medical Journal of Tabriz University of Medical Sciences \& Health Services. 2009; 31(1):57-60.

30. Heffernan TM, Ling J, Parrott AC, Buchanan T, Scholey AB, Rodgers J. Self-rated everyday and prospective memory abilities of cigarette smokers and non-smokers: a web-based study. Drug Alcohol Depend 2005; 78(3):235-41.

31. Hill R, Nilsson LG, Nybery L, Bäckman L. Cigarette smoking and cognitive performance in healthy Swedish adults. Age Ageing 2003; 32(5):548-50.

32. Wang CC, Lu TH, Liao WC, Yuan SC, Kuo PC, Chuang HL, et al. Cigarette smoking and cognitive impairment: a 10-year cohort study in Taiwan. Arch Gerontol Geriatr 2010; 51(2):143-8.

33. Momtaz YA, Ibrahim R, Hamid TA, Chai ST. Smoking and cognitive impairment among older persons in Malaysia. Am J Alzheimers Dis Other Demen 2015; 30(4):405-11.

34. Elfering A, Grebner S, Dudan A. Job characteristics in nursing and cognitive failure at work. Saf Health Work 2011; 2(2):194-200.

35. Allahyari T, Rangi NH, Khalkhali H, Khosravi Y. Occupational cognitive failures and safety performance in the workplace. Int J Occup Saf Ergon 2014; 20(1):175-80. 